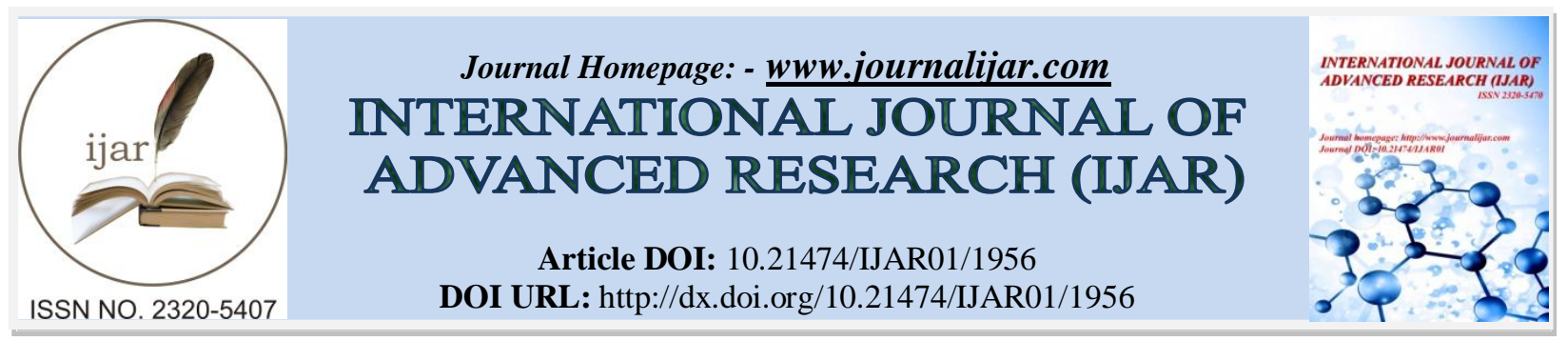

RESEARCH ARTICLE

\title{
MOLECULAR EVALUATION OF MMP9 IN IRAQI BREAST CANCER PATIENTS.
}

Sammar Faisal Jaafer and Asstant Prof. Dr. Ismail Hussein Aziz.

Institute of genetic engineering and biotechnology for postgraduate studies Baghdad University.

\section{Manuscript Info}

Manuscript History

Received: 12 August 2016

Final Accepted: 22 September 2016

Published: October 2016

Key words:-

breast cancer, MMP, MMP9.

\section{Abstract}

Breast cancer is the most frequently diagnosed cancer and the leading cause of cancer deaths in females worldwide. One of the main challenges in mammary cancer research is now to identify key proteins modulating tumor invasion, which can serve as early markers for invasive tumors as well as new drug targets. High level of MMP-9 expression in breast cancer is positively correlated with enhanced tumor cell invasion and metastasis and with enhanced progression and poorer prognosis. This study involved collection of 70 tissue samples after surgery 30 samples for patients and 40 samples for control. The study revealed that the percentage of patients that gave positive result for gene expression of MMP9 was $46.66 \%$ while the percentage of control samples that gave positive gene expression for MMP9 was $62.5 \%$. This study found an increase in MMP9 gene expression in cancer patients. The cancer cells are expressing MMP9 in 5.263 fold higher than the expression of MMP9 in the cells of control samples.

Copy Right, IJAR, 2016,. All rights reserved.

\section{Introduction:-}

Cancer is an abnormal growth of cells caused by multiple changes in gene expression leading to dysregulated balance of cell proliferation and cell death and ultimately evolving into a population of cells that can invade tissues and metastasize to distant sites (Ruddon, 2007). Breast cancer is the most frequently diagnosed cancer and is the leading cause of cancer deaths in females worldwide (Sun et al., 2012). Despite continued improvements in diagnosis, surgical techniques and chemotherapy, lethality from breast cancer remains high (Hallet et al., 2013). Despite vast improvement in the overall survival rate of patients with noninvasive breast cancer, advanced metastatic breast cancer remains a life-threatening disease. One of the main challenges in mammary cancer research is now to identify key proteins modulating tumor invasion, which can serve as early markers for invasive tumors as well as new drug targets (Borges et al., 2013).

The Matrix metalloproteinases MMPs comprise a family of 24 zinc dependent endopeptidases with broad spectrum of enzymatic activity against all components of the extracellular matrix ( ECM ) and basement membrane (Schveigert et al., 2013). Based on their structure and substrate specificity. MMPs can be divided into five groups: collagenases, gelatinases, stromelysins, matrilysins and membrane-type MMPs (MT-MMPs) (Decock et al., 2008). MMPs are usually minimally expressed in normal physiological conditions and thus homeostasis is maintained. However, MMPs are regulated by hormones, growth factors, and cytokines, and are involved in ovarian functions (Verma and Hansch, 2007). MMP-9 is synthesized by endothelial cells, fibroblasts, and hematopoietic cells. In a transgenic mice study, the lack of MMP-9 has been shown to decrease the incidence of invasive tumors (Schveigert

Corresponding Author:- Sammar Faisal Jaafer.

Address:- Institute of genetic engineering and biotechnology for postgraduate studies Baghdad University. 
et al., 2013). High level of MMP-9 expression in breast cancer is positively correlated with enhanced tumor cell invasion and metastasis and with enhanced progression and poorer prognosis (Hallet et al., 2013).

\section{Samples Collection:-}

The study involved collection of 70 tissue samples that were taken from surgical operations from Baghdad teaching hospital/medical city. The samples include 40 samples for control that include cases of fibroadenoma, normal breast tissues, ductectasia and accessory breast. The other 30 samples are from patients of breast cancer that include cases of mastectomy, recurrent lymph node post mastectomy, removal of the cancerous mass. Figure (1) shows case of mastectomy.

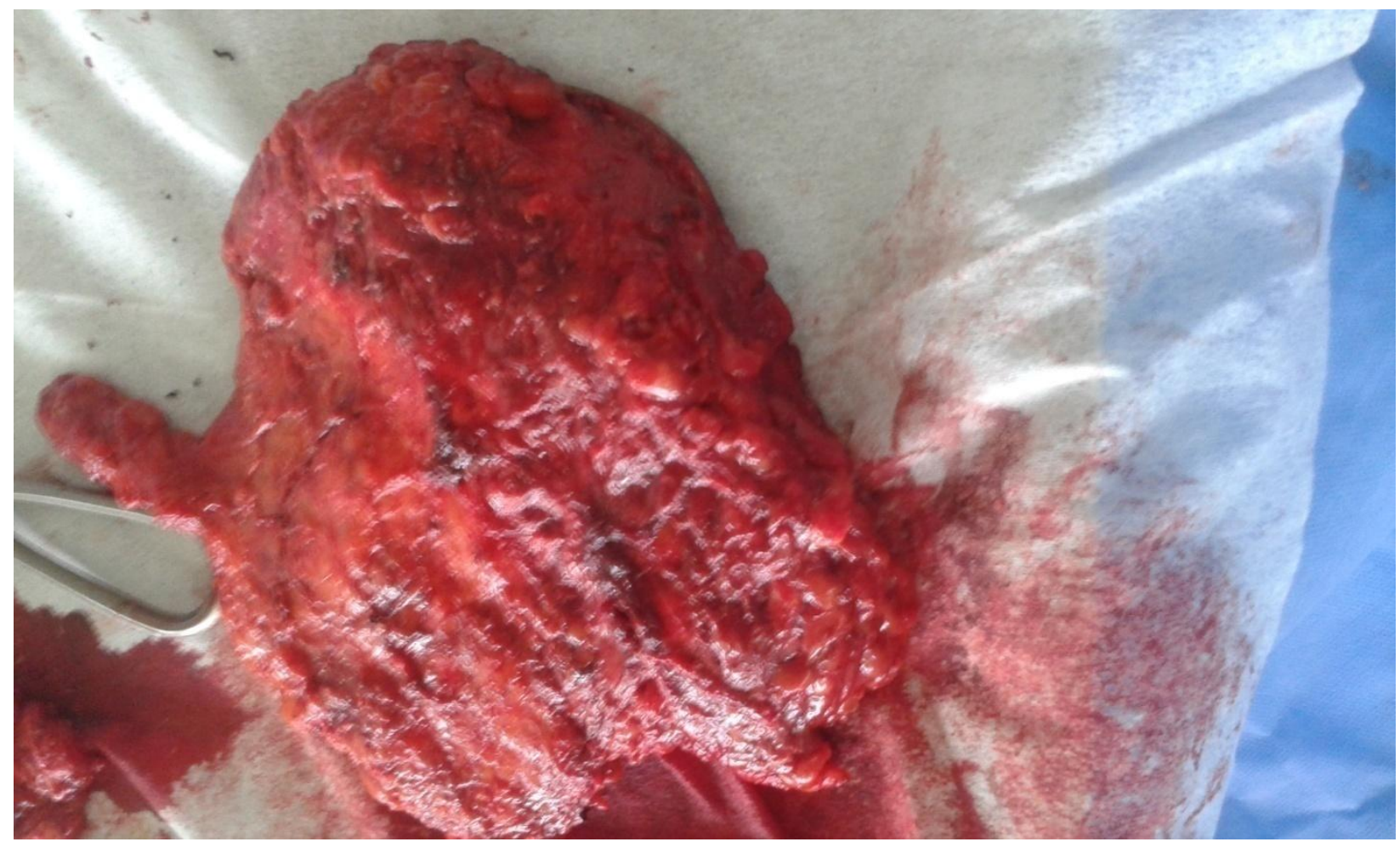

Figure 1:- Mastectomy (This Study)

\section{Materials and Methods:-}

RNA extraction and cDNA synthesis: RNA was extracted from tissue samples using (Tissue RNA PrepMate kit, Bioneer) according to the protocol of the manufacturer with modifications, also RNA was extracted from tissue samples using ( Trizol, Applied Biosystem) according to the protocol of the manufacturer with modifications. Then cDNA was synthesized using (AccuPower ${ }^{\mathrm{R}}$ RocketScript $^{\mathrm{TM}}$ RT PreMix kit, Bioneer) according to the protocol of the manufacturer with modifications. After synthesis of cDNA gel electrophoresis was done using $1 \%$ agarose concentration to ensure the presence of cDNA as shown in figure (2): 


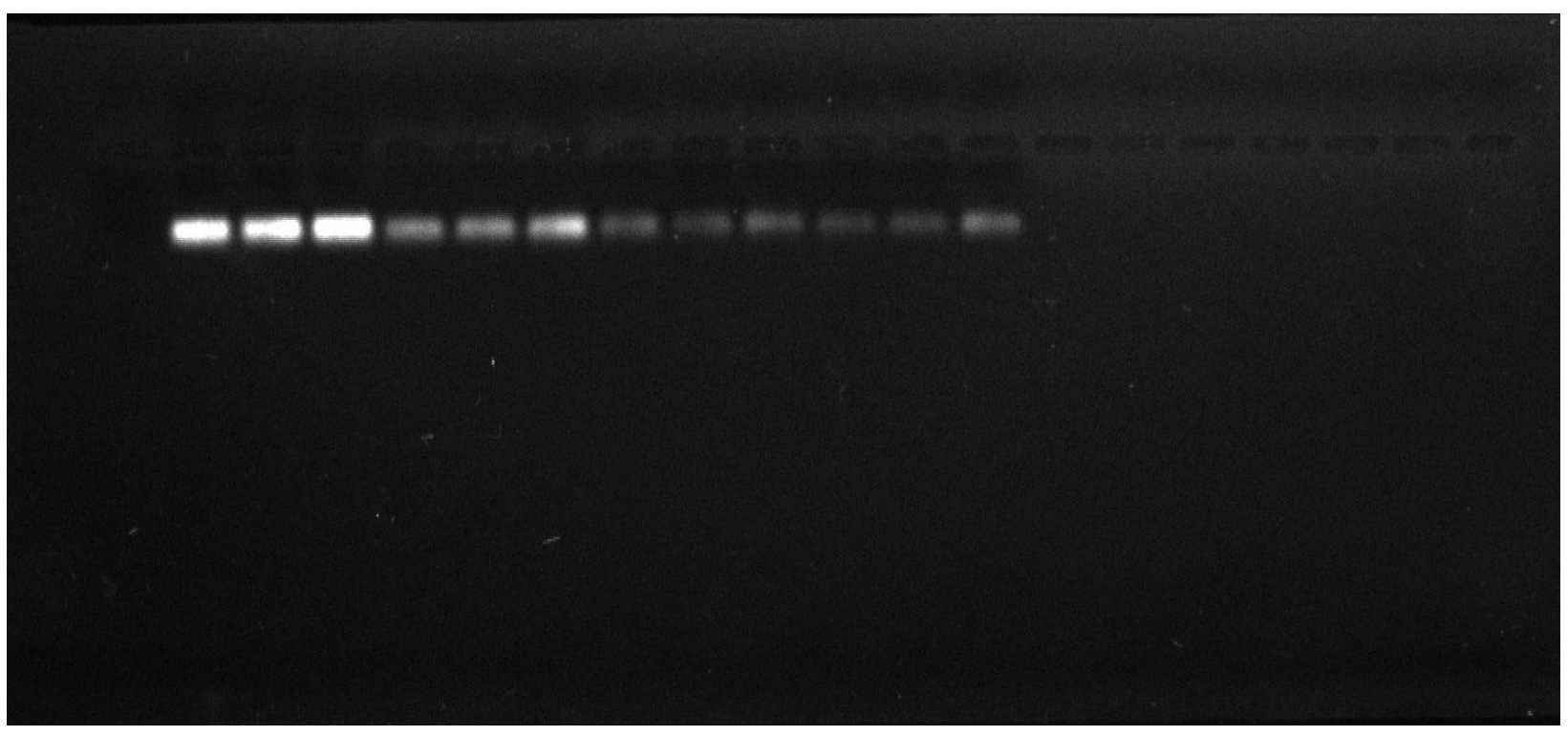

Figure 2:- electrophoresis for cDNA samples, agarose concentration 1\%, time 15 minutes, 100 volt.

\section{Quantitative Real time PCR:-}

Quantitative Real time PCR was done for cDNA samples by the use of syber Green master mix using (Accupower GreenStar ${ }^{\mathrm{TM}}$ qPCR PreMix, Bioneer) according to the protocol and the program of the manufacturer. The following primers were used: (MMP9 forward primer: 5-CCTTCCTTATCGCCGACAAG3') and (MMP9 reverse primer: 5' TGAACAGCAGCATCTTCCCC-3') and GAPDH was used as a house keeping gene, (GAPDH forward primer: 5' TCCTGTGGCATCCACGAAACT-3') and (GAPDH reverse primer: 5'GAAGCATTTGCGGTGGACGAT-3').

\section{Results:-}

Real time PCR data were determined as Threshold cycle $(\mathrm{Ct})$ values. The $\mathrm{Ct}$ value is inversely proportional to the amount of gene expression which means that the low $\mathrm{Ct}$ values indicate a high gene expression while the high $\mathrm{Ct}$ values indicate a low gene expression. The following equations were used (Thomas and Kenneth, 2008):

$\Delta \mathrm{CT}$ sample $=\mathrm{Ct}$ sample $-\mathrm{Ct}$ house keeping gene

$\Delta \mathrm{CT}$ calibrator $=\mathrm{Ct}$ control $-\mathrm{Ct}$ house keeping gene

The normalized $\Delta \mathrm{CT}$ data are used to calculate the relative gene expression fold change using a selected calibrator (control sample):

$\Delta \Delta \mathrm{CT}=\Delta \mathrm{CT}$ sample $-\Delta \mathrm{CT}$ calibrator

Fold Change $=2^{-} \Delta \Delta \mathrm{Ct}$

In this study the percentage of patients that gave positive result for gene expression of MMP9 was $46.66 \%$ while the percentage of control samples that gave positive gene expression for MMP9 was $62.5 \%$. Figure (3)

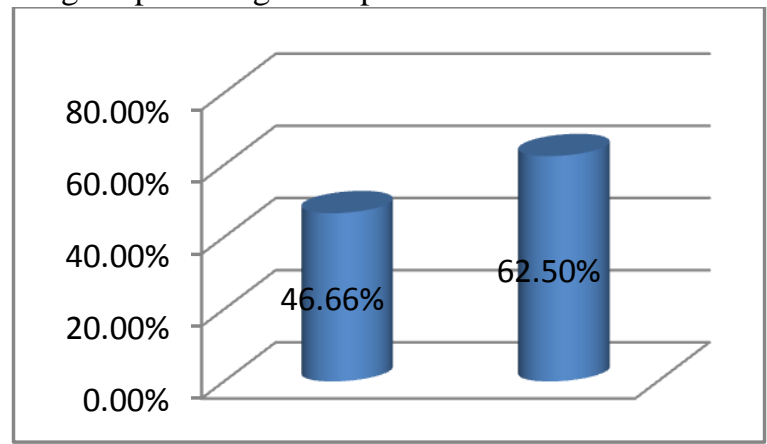

Figure 3:- the percentage of patients and controls that gave positive result for gene expression of MMP9 
This study found an increase in MMP9 gene expression in cancer patients. The cancer cells are expressing MMP9 in 5.263 fold higher than the expression of MMP9 in the cells of control samples. Figure (4)

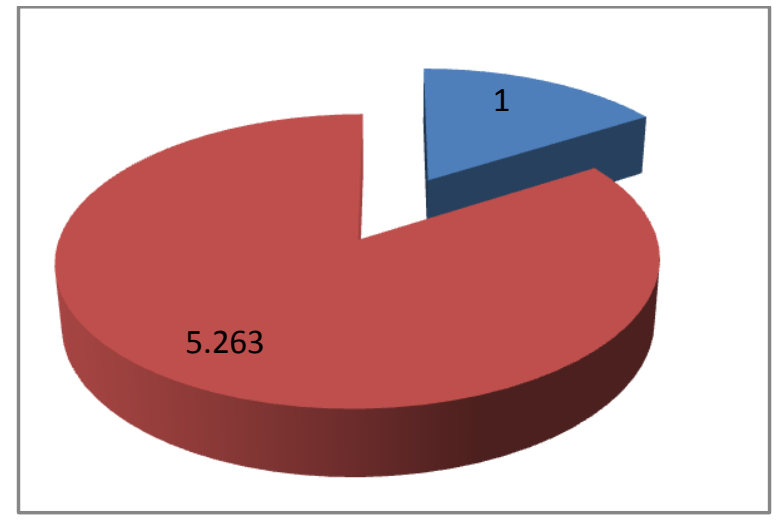

Figure 4:- increasing in gene expression of MMP9 in patients compared with controls

\section{Discussion:-}

A study found that the expression of MMP9 is upergulated in cancer tissues (Benson et al., 2013). Another study found that MMP9, MMP11 and MMP28 mRNA expression was higher in breast cancer tissue, also the survival rate was lower for the patients with positive MMP9 expression (Schveigert et al., 2013). While a study on human brain glioma found that gelatinase-B (MMP9) is primarily involved in tumor neovascularization (Forsyth et al., 1999). A study showed higher MMP9 expression in samples from tumors than those from adjacent non tumor tissue samples (Figueira et al., 2009). In colorectal cancer, MMP9 generally had an increased but inconstant expression in cancer cells. The strongest expression was found in moderately and poorly differentiated cancers and a lower expression in well differentiated colorectal cancers (Georgescu et al., 2015). MMP9 is mainly expressed by malignant cells (Westermarck et al., 1999). Possible mechanisms by which MMPs contribute to cancer initiation or tumor cell growth include promotion of angiogenesis, activation of stimulating growth factors or their receptors and inactivation of inhibiting growth factors (Duffy et al., 2000). The evidence for MMPs as active contributors to cancer progression comes from animal studies in transplantation assays, relatively benign cancer cells acquire malignant properties when MMP expression is upregulated. Conversely, highly malignant cells become less aggressive when MMP expression or activity is reduced (Egeblad and Werb, 2002). High levels of MMP9 have been shown to strongly correlate with tumor aggressiveness and poor prognosis in various human cancers (Chen et al., 2015).

\section{Conclusion:-}

MMP9 is a good biomarker for early detection of breast cancer because its expression is elevated in case of malignancy more than in case of benign tumors.

\section{Acknowledgment:-}

I would like to thank Allah subhanh, my family, the dean of institute of genetic ngineering and biotechnology, my adviser, the doctors and the staff in Baghdad teaching hospital and everybody helped me.

\section{Refrences:-}

1. Ruddon.R.W.(2007) . Cancer biology. Fourth edition.

2. Sun, Q.; Yang;Y-M. ; Yu ,S-H. , Zhang, Y-X., He, X-G. , Sun, S-S. , Liang, X.S. and Pang, D. (2012). Covariation of copy number located at 16q22.1: New evidence in mammary ductal carcinoma. Oncology Reports. Vol. 28: 2156-2162.

3. Hallet, M.A.; Teng, B.; Hasegawa, H.; Schwab, L.P.; Seagroves, T.N. and Pourmotabbed , T.(2013). Antimatrix metalloproteinase-9 DNAzyme decreases tumor growth in the MMTV-PyMT mouse model of breast cancer. Breast Cancer Research. 15:R12

4. Borges, S. , Döppler, H. ; Perez, E.A. , Andorfer, C.A. ; Sun, Z. ; Anastasiadis, P.Z.; Thompson, E.A. ; Geiger, X.J. and Storz, P. (2013). Pharmacological reversion of epigenetic silencing of the PRKD1 promoter blocks breast tumor cell invasion and metastasis. Breast Cancer Research. 15:R66. 
5. Schveigert,D.; Cicenas,S. ; Bruzas,S. ; Samalavicius.NE. , Gudleviciene,Z. and Didziapetriene,J. (2013).The value of MMP -9 for breast and non small cell lung cancer patients'survival. Advances in medical sciences. Vol.58 (1): 73-82.

6. Decock, J.; Paridaens, R. and Ye, S. (2008). Genetic polymorphisms of matrix metalloproteinases in lung, breast and colorectal cancer. Clin Genet. Vol. 73:197-211.

7. Verma,R.P. and Hansch,C. (2007). Matrix metalloproteinases (MMPs): Chemical-biological functions and (Q)SARs. Bioorganic \& medicinal chemistry. Vol.15: 2223-2268.

8. Thomas, D.S. and Kenneth, J.L. (2008). Analyzing real-time PCR data by the comparative Ct method. Nature Protocol. 3(6): 1101-1108.

9. Benson, C.S.; Babu, S.D.; Radhakrishna, S.; Selvamurugan, N. and Sankar, B.R. (2013). Expression of matrix metalloproteinases in human breast cancer tissues. Disease Markers. 34: 395-405.

10. Forsyth, P.A., Wong.H. , Laing, T.D. , Rewcastle, N.B. , Morris, D.G. , Muzik, H. , Leco, K.J. , Johnston, R.N. , Brasher, P.M.A., Sutherland, G. and Edwards, D.R. (1999). Gelatinase-A (MMP-2), gelatinase-B (MMP-9) and membrane type matrix metalloproteinase-1 (MT1-MMP) are involved in different aspects of the pathophysiology of malignant gliomas. British Journal of Cancer. 79:1828-1835.

11. Figueira, R.C.S , Gomes.L.R. , Neto, J.S., Silva, F.C. Silva, I.D.C.G. and Sogayar, M. (2009). Correlation between MMPs and their inhibitors in Breast cancer tumor tissue specimens and in cell lines with different metastatic potential. BMC Cancer 9:20.

12. Georgescu, E.F.; Mogoantă, S.Ş.; Costachi, A.; Părvănescu, V.; Totolici, B.D.; PătraŞcu, Ş. and Stănescu, C. (2015). The assessment of matrix metalloproteinase-9 expression and angiogenesis in colorectal cancer. Romanian Journal of Morphology and Emberiology. Vol. (56)3: 1137-1144.

13. Westermarck, J. and Kähäri, V.M. (1999). Regulation of matrix metalloproteinase expression in tumor invasion. The FASEB Journal. Vol. 13: 781-792.

14. Duffy, M.J.; Maguire, T.M.; Hill.A. , McDermott, E. and Higgins, N.O. (2000). Metalloproteinases: role in breast carcinogenesis, invasion and metastasis. Review/ Journal of Breast Cancer Research . Vol. 2. No. 4: 252257.

15. Egeblad, M. and Werb, Z. (2002). New functions for the matrix metalloproteinases in cancer progression. Reviews/ Journal of Cancer. Volume 2: 161-165.

16. Chen, J.; Liu, X.; Jiao, H.; Peng, L.; Huo, Z.; Yang, W.; Shen, Q.; Li, T. and Liu, Q. (2015). Prognostic and clinical significance of STAT3 and MMP9 in patients with gastric cancer: a meta-analysis of a Chinese cohort. Int.J.Clin.Exp.Med. Vol. 8 (1): 546-557. 